\title{
Aspectos éticos da pesquisa científica
}

\section{Ethical aspects of scientific research}

\author{
Laîs Záu Serpa de Araújo*
}

\begin{abstract}
RESUMO: A declarada importância da relação ética no desenvolvimento das experimentações em seres humanos tem sido observada nos mais diferentes padrões. O texto aborda a complexidade de procedimentos, normativas, análise de riscos e beneficios e as inúmeras contribuições dada a significativa reflexão pertinente e atual sobre o tema. DESCRITORES: Pesquisa; Ética em pesquisa.
\end{abstract}

\begin{abstract}
The professed importance of ethical relations in the development of researches in human beings has been observed in many standards. This text approaches the complexity of procedures, guidelines, risk and benefit analyses, and innumerable contributions, given the significance of pertinent and up-to-date consideration on the matter. DESCRIPTORS: Research; Ethics, research.
\end{abstract}

\section{INTRODUÇÃO}

Se houve um tempo em que muitos pesquisadores acreditavam que sua firme determinação de fazer o bem, sua integridade de caráter e seu rigor científico eram suficientes para assegurar a eticidade de suas pesquisas, nos dias de hoje essa concepção já não é mais objeto de consenso. O grande desenvolvimento e a crescente incorporação de novas tecnologias no campo dos cuidados em saúde; a maior difusão do conhecimento científico através dos meios de comunicação social tradicionais e, em particular, através da Internet, assim como a ampliação dos movimentos sociais em defesa dos direitos individuais e coletivos, fizeram com que a discussão sobre a ética aplicada à saúde passasse a ter como interlocutores freqüentes filósofos, teólogos, juristas, sociólogos e, sobretudo, os cidadãos, seja enquanto usuários do sistema de saúde seja como sujeitos, objetos de pesquisas científicas (Palácios et al. $\left.{ }^{23}, 2002\right)$.

Essas novas situações que o homem vivencia e que nele provocam duas sensações, por vezes antagônicas - a esperança e a perplexidade - são, sem dúvida nenhuma, fruto das pesquisas científicas. A busca incessante por novos conhecimentos e conseqüentemente de novas tecnologias é uma característica do homem. Quase que diariamente somos surpreendidos por novas descobertas. Algumas chegam e trazem esperança para so- lução de problemas ou necessidades, outras provocam inquietações como, recentemente, a discussão sobre clonagem humana. Mas, não é privilégio dos dias atuais essas preocupações. Desde os primórdios da humanidade que as descobertas são responsáveis pela desconfiança e preocupação com o que pode acontecer no futuro.

As descobertas cientificas se acentuaram, nas ciências da saúde, principalmente nos últimos 50 anos. Muitas dessas novidades provocaram, e algumas ainda provocam, discussões éticas. O advento da anestesia e da penicilina, a descoberta da dupla hélice do DNA, o primeiro transplante de rim, as máquinas para diálise, a pílula anticoncepcional, o transplante de coração, o primeiro bebê de "proveta", a epidemia da AIDS, o projeto genoma humano e, recentemente, a clonagem de seres humanos, são exemplos palpáveis e concretos da importância da pesquisa científica, mas, também, da pertinência da discussão sobre ética na pesquisa.

A pesquisa é uma atividade tão representativa e importante na sociedade que o número de profissionais dedicados a essa ocupação aumentou significativamente. A partir do século XVII, a cada 10-15 anos esse número duplicou. Hoje os pesquisadores atuantes representam numericamente mais que a soma de todos os cientistas que o mundo já teve. Esse contingente de cientistas, nos vá-

* Professora das disciplinas de Bioética, Medicina Legal e Ética Médica da Escola de Ciências Médicas de Alagoas/Fundação Universitária de Ciências da Saúde de Alagoas, Coordenadora do Comitê de Ética em Pesquisa da Escola de Ciências Médicas de Alagoas/Fundação Universitária de Ciências da Saúde de Alagoas, Especialista em Odontologia Legal pela Universidade de São Paulo, Doutoranda em Saúde Pública, área de concentração em Bioética, da Escola Nacional de Saúde Pública/Fundação Oswaldo Cruz. 
rios campos da ciência, dia-a-dia nos traz novos conhecimentos e novas descobertas, os quais inevitavelmente acabarão, de uma ou outra maneira, atingindo o homem, para o bem ou para o mal (Hossne, Vieira ${ }^{17}$, 1995).

O termo "pesquisa" diz respeito a uma classe de atividades cujo objetivo é desenvolver ou contribuir para o conhecimento generalizável. O conhecimento generalizável consiste em teorias, princípios ou relações, ou no acúmulo de informações sobre as quais está baseado, que possam ser corroboradas por métodos científicos aceitos de observação e inferência. No presente contexto, "pesquisa" inclui estudos relativos à saúde humana. Geralmente a palavra "pesquisa" é modificada pelo adjetivo "biomédica", para indicar que se refere à pesquisa relacionada à saúde (Pessini, Barchifontaine $\left.{ }^{26}, 1996\right)$.

Os profissionais de saúde, no exercício de sua profissão, utilizam em seus pacientes as informações que foram obtidas através das pesquisas científicas. Entretanto, como afirmam Pessini e Barchifontaine, a pesquisa envolvendo seres humanos deve ser diferenciada da prática da medicina, saúde pública e de outras formas de assistência à saúde, que se destinam a contribuir diretamente para a saúde de indivíduos e comunidades (Pessini, Barchifontaine ${ }^{26}$, 1996).

A importância das pesquisas nas ciências da saúde é inegável, assim como é necessária, em determinados momentos, a utilização de seres humanos como sujeitos, objeto da pesquisa cientifica. Como disse Oliveira, abdicar das experimentações em humanos poderá, em alguns casos, constituir uma grande irresponsabilidade, acarretando riscos incalculáveis, pois nem sempre o que funciona in vitro, em culturas celulares, funcionará como o esperado in vivo (aqui no sentido do organismo humano em sua totalidade) (Oliveira ${ }^{22}$, 1997). É a partir dessa reflexão que queremos discutir alguns aspectos das pesquisas que envolvem seres humanos.

\section{EXPERIMENTAÇÕES COM SERES HUMANOS}

No decorrer dos séculos, experimentações com seres humanos têm sido realizadas com diferentes padrões de qualidade e ética. A história relata vários exemplos de utilização de seres humanos em estudos e pesquisas que chocaram, e ainda chocam a humanidade. Nesses casos, a ausência de mecanismos de controle fundamentados em critérios éticos e morais, resultou em abusos de experi- mentos e na "cobaização" do ser humano (Hossne, Vieira $\left.^{17}, 1995\right)$.

Infelizmente, a humanidade é testemunha desses excessos ocorridos em nome da ciência. Alguns desses casos se tornaram emblemáticos e merecem ser lembrados.

$\mathrm{Na}$ Inglaterra, em 1721, o cirurgião inglês Charles Maitland, inoculou variola em 6 prisioneiros com a promessa de liberdade (Howard-Jones ${ }^{18}$, 1982).

Dos exemplos ocorridos na Alemanha é importante citar: até 1900, em vários estudos, inocularam doenças venéreas incuráveis em seres humanos que não deram seu consentimento (Pappworth $\left.^{24}, 1968\right)$; os casos de transplantes de células cancerosas; exposição proposital à febre tifóide; manipulação de cérebros de mulheres com convulsões e numerosas pesquisas em recém-nascidos, grávidas, loucos e moribundos (Gracia $^{15}$, 1998); entre agosto de 1942 a maio de 1943, em Dachau, o Dr. Sigmund Rascher realizou vários experimentos, entre eles o da resistência ao frio. O Tribunal de Nuremberg julgou 23 médicos. Destes, 16 foram declarados culpados e 7 condenados à morte $\left(\mathrm{Gafo}^{12}\right.$, 1994).

Nos Estados Unidos temos muitos experimentos que merecem ser conhecidos: no século XIX, em Michigan, o cirurgião William Beaumont manteve aberta uma ferida de bala no tubo digestivo, por 3 anos, com a colaboração do paciente. Esse experimento foi considerado por alguns como um dos grandes êxitos da medicina norte-americana (Beaumont $^{3}$, 1883); entre 1932 e 1972, em Tuskegee, no Alabama, o Serviço Nacional de Saúde e Assistência selecionou 400 homens negros infectados por sífilis para estudar a história natural da doença. Em 1950 foi descoberta a penicilina, substância utilizada até hoje no tratamento da sífilis, entretanto esses homens não foram tratados, nem informados da possibilidade de tratamento $(\mathrm{Ca}-$ $\left.\operatorname{plan}^{7}, 1992\right)$; na Universidade de Vanderbilt, Tennesee, mulheres pobres grávidas foram submetidas à radiação com dose 30 vezes maior que a dose considerada inócua, e, na Universidade de Chicago, entre setembro de 1950 a novembro de 1952, foi ministrado, sem consentimento, dietilestilbestrol para evitar perdas de gestação para $1.000 \mathrm{mu}-$ lheres. Após 20 anos, os nascidos começaram a ter taxas incomuns de câncer, motivo pelo qual veio a conhecimento esta informação (Beecher ${ }^{5}$, 1996). Na Escola Willowbrook, em Nova York, entre 1950 e 1970, foi inoculado vírus da hepatite C em defici- 
entes mentais (Godin, Glantz $\left.{ }^{14}, 1994\right)$; na década de 60, no Jewish Chronic Disease Hospital, foram inoculadas células cancerosas em judeus idosos internados $\left(\mathrm{Gracia}^{15}, 1998\right)$; em Oregon e Washington, no ano de 1963, 131 presos foram contratados, por US $\$ 200,00$ cada um, para serem submetidos à radiação de 600 roentgen nos genitais (a máxima radiação anual permitida é de 6 roentgen) (Kieffer ${ }^{19}$, 1983) e em San Antonio, no Texas, em 1971, numa pesquisa com anticoncepcionais em mulheres pobres de origem hispânica, multiparas, que não foram avisadas sobre a utilização de placebo, dez dessas mulheres tiveram gravidez indesejada (Calvo $\left.{ }^{6}, 1971\right)$.

No Japão, entre 1930 e 1945 na Manchúria, durante a Segunda Guerra Mundial, prisioneiros chineses foram submetidos a experimentos com morte direta ou indireta, totalizando 3.000 mortes. Foram feitos testes com insetos e todos os tipos de germes. O objetivo era provar a resistência humana ao botulismo, antrax, brucelose, cólera, disenteria, febre hemorrágica, sifilis, entre outros e, também aos raios $\mathrm{X}$ e ao congelamento. O exército americano foi cúmplice desses fatos $\left(\right.$ Reich $^{27}$, 1995).

Por si só, o progresso científico não justifica qualquer tipo de experimentação. Mesmo quando os resultados dos experimentos prometem em longo prazo beneficiar a humanidade, nem por isso eles ficam ipso facto legitimados. Todo avanço científico que é feito pisoteando a dignidade humana leva consigo uma carga negativa e deve ser repensado (Pessini, Barchifontaine ${ }^{26}$, 1996).

\section{NORMAS ÉTICAS PARA PESQUISA COM SERES HUMANOS}

Os abusos cometidos em nome do Estado e da Ciência, apurados e denunciados mundialmente em 1947, no relatório final do Tribunal Internacional de Nuremberg, levou à elaboração do primeiro código de conduta em pesquisas, internacionalmente aceito - o Código de Nuremberg (1947) (Palácios et al. ${ }^{23}, 2002$ ).

Os deslizes éticos já ocorriam antes do Código de Nuremberg. A investigação histórica revela várias situações em que a ética não foi respeitada, às vezes, nem sequer foi cogitada. E, após o aparecimento do Código de Nuremberg, não obstante a dramaticidade do contexto em que nasceu, as infrações éticas, infelizmente, continuaram e continuam a ocorrer (Hossne, Vieira $\left.{ }^{17}, 1995\right)$.
A necessidade de regulamentar as pesquisas em humanos, de forma a proteger as populações a elas submetidas e a pouca influência do Código de Nuremberg sobre as práticas de pesquisa está entre as condições que deram origem à chamada Declaração de Helsinque. Elaborada e aprovada pela Associação Médica Mundial, a primeira versão desta Declaração data de 1964 (Palácios et al. ${ }^{23}$, 2002). A nova versão da Declaração de Helsinque foi votada na $52^{\mathrm{a}}$ Assembléia Geral da Associação Médica Mundial na cidade de Edimburgo no ano 2000 (Schramm, Kottow ${ }^{28}, 2000$ ).

No Brasil, o Conselho Nacional de Saúde (CNS) aprovou um documento que teve como objetivo criar parâmetros éticos para as pesquisas na área da saúde, a Resolução CNS 01 (1988). Posteriormente, esse documento foi substituído pela resolução CNS 196 (1996).

A partir da Resolução CNS 196 (1996) e das resoluções complementares, o desenvolvimento das pesquisas com seres humanos, no Brasil, tomou um novo rumo e os pesquisadores tiveram que se adaptar ou estão se adaptando a essa nova realidade (Araújo ${ }^{1}$, 1999).

A Resolução CNS 196 (1996) define pesquisa com seres humanos como aquela "que, individual ou coletivamente, envolva o ser humano de forma direta ou indireta, em sua totalidade ou partes dele, incluindo o manejo de informações ou materiais". Essa definição é de fundamental importância, pois não restringe o conceito de pesquisa com seres humanos apenas àquelas realizadas nas ciências da saúde. Inclui toda modalidade de pesquisa que direta ou indiretamente envolva seres humanos e, mais, que o manejo de informações e a utilização de partes do corpo, como por exemplo, dentes, são consideradas pesquisa com seres humanos e devem seguir parâmetros éticos.

Vale ressaltar que a Resolução CNS 196 (1996) é considerada uma recomendação ética e não uma lei. Isso não a torna mais ou menos relevante. $\mathrm{O}$ fato é que os periódicos e os eventos científicos, nacionais e internacionais, têm solicitado a comprovação de que o trabalho foi aprovado previamente por um Comitê de Ética em Pesquisa.

\section{COMITÊ DE ÉTICA EM PESQUISA}

Por volta de 1960 começa a ter aceitação a idéia de que os experimentos com seres humanos precisam ser revistos, ainda em sua fase de projeto, por uma comissão multidisciplinar (Hossne, Viei $\left.\mathrm{ra}^{17}, 1995\right)$. 
Os Comitês de Ética em Pesquisa surgem com a tarefa de considerar as condições de incerteza no desenvolvimento das pesquisas e ponderar os conflitos de maneira imparcial, sem deixar de proteger a parte mais frágil, que é quase sempre o sujeito ou a população investigados, mas pode ser, também, o próprio pesquisador, pressionado por agências financiadoras de pesquisa, pela estrutura competitiva da pesquisa e por valores imperantes (Schramm, Kottow ${ }^{28}, 2000$ ).

No Brasil, a resolução CNS 196 (1996) define Comitês de Ética em Pesquisa (CEPs) como: "colegiados interdiciplinares e independentes, com 'múnus público', de caráter consultivo, deliberativo e educativo, criados para defender os interesses dos sujeitos da pesquisa em sua integridade e dignidade e para contribuir no desenvolvimento da pesquisa dentro de padrões éticos". E, Comissão Nacional de Ética em Pesquisa - CONEP/MS como: "uma instância colegiada, de natureza consultiva, deliberativa, normativa, independente, vinculada ao Conselho Nacional de Saúde" (Resolução CNS 196/96).

Toda pesquisa que envolva direta ou indiretamente os seres humanos tem obrigatoriamente que ser apreciada por um CEP. Às vezes por mais de um CEP, como no caso dos estudos multicêntricos, quando o mesmo protocolo tem obrigatoriamente que ser analisado por tantos CEPs quantas instituições participarem da pesquisa (Palácios et $\left.a .^{23}, 2002\right)$.

Os CEPs, quanto à sua composição, são multidisciplinares, formados por indivíduos das mais diversas áreas do conhecimento humano. Seu objetivo maior é preservar a integridade dos sujeitos, objeto da pesquisa científica bem como, apreciar previamente os projetos de pesquisa.

Os CEPs no Brasil contemplam também a participação de representante dos usuários da instituição, conforme estabelece a resolução CNS 196 (1996). Hoje já contamos com mais de 400 CEPs espalhados em todo Brasil. Cada instituição de pesquisa deve criar um ou mais comitês conforme a necessidade e inscrever esses comitês na CONEP.

O pesquisador deve enviar para o CEP de sua instituição um documento denominado pela CNS 196 (1996) protocolo de pesquisa, definido como "documento contemplando a descrição da pesquisa em seus aspectos fundamentais, informações relativas ao sujeito da pesquisa, à qualificação dos pesquisadores e a todas as instâncias responsáveis".

Para sua análise, o CEP utilizará as informações fornecidas pelo pesquisador, através do protocolo de pesquisa. Entre os aspectos avaliados pelo comitê, devemos citar a ponderação dos riscos e beneficios que pode estar contemplada na introdução do projeto, ou o pesquisador pode abrir um capítulo especial para tratar dessa questão. A competência do pesquisador para conduzir a pesquisa também faz parte da avaliação do CEP e é comprovada através do currículo do pesquisador ou pesquisadores se for o caso, envolvidos na pesquisa. O consentimento livre esclarecido e o termo de consentimento, igualmente estão inclusos na análise do comitê.

\section{CONSENTIMENTO LIVRE E ESCLARECIDO}

A resolução CNS 196 (1996) define o consentimento livre e esclarecido como "anuência do sujeito da pesquisa e/ou de seu representante legal, livre de vícios (simulação, fraude ou erro), dependência, subordinação ou intimidação, após explicação completa e pormenorizada sobre a natureza da pesquisa, seus objetivos, métodos, benefícios previstos, potenciais de riscos e o incômodo que esta possa acarretar, formulada em um termo de consentimento, autorizando sua participação voluntária no experimento". O consentimento livre e esclarecido do participante é uma exigência não só do Brasil, mas de todos os códigos internacionais e é, sem dúvida, um dos pilares da ética nas pesquisas científicas.

A investigação biomédica com seres humanos só pode ser feita mediante consentimento. É ele que transforma o que seria simplesmente uso da pessoa em participação consciente num empreendimento científico (Hossne, Vieira $\left.{ }^{17}, 1995\right)$. Mas, na realidade, o consentimento é freqüentemente dificil de se obter. Porém, mesmo diante de várias dificuldades, o consentimento livre e esclarecido é uma meta que o pesquisador deve atingir. Essa necessidade é baseada em três razões (Beecher ${ }^{4}$, 1966):

- Ética - nenhum homem tem o privilégio de escolher os participantes para um procedimento arriscado sem o conhecimento e acordo do indivíduo.

- Sociológica - a sociedade não tolerará a dominação de um pesquisador no que diz respeito a sua saúde ou vidas. Estudos que não têm o apoio tácito do público não florescerão. 
- Legal - a lei protege a integridade e a vida humanas e é ofensiva quanto à invasão do corpo.

Quando se fala em consentimento, deve-se analisar separadamente três fatores que o integram: a informação, a vontade e a competência (Pelaez ${ }^{25}$, 1988). A informação é a base da decisão autônoma, necessária para que o participante possa consentir ou recusar. O consentimento livre e esclarecido requer informações adequadas, compreendidas pelo paciente. A pessoa pode ser informada, mas não significa que esteja esclarecida (Muñoz, Fortes ${ }^{21}, 1998$ ). A vontade é expressa através do consentimento. Todavia ela pode estar condicionada a uma relação de dependência ou respeito ao pesquisador. O consentimento deve ser livre e nada pode interferir nessa decisão $\left(\mathrm{Pelaez}^{25}\right.$, 1988).

A questão do consentimento é especialmente grave quando o experimento é conduzido com pessoas vulneráveis, isto é, com pessoas que não têm condições de proteger os próprios interesses (Hossne, Vieira $\left.{ }^{17}, 1995\right)$. A vulnerabilidade refere-se ao estado de pessoas ou grupos que, por quaisquer razões ou motivos, tenham a sua capacidade de autodeterminação reduzida. A incapacidade refere-se ao possivel sujeito da pesquisa que não tenha capacidade civil para dar seu consentimento livre e esclarecido (Resolução CNS 196, 1996). Nos casos em que a competência do indivíduo é diminuída, o consentimento pode ser dado por outra pessoa diferente do sujeito da pesquisa. O consentimento livre e esclarecido deve ser feito por um procurador legal que assumirá a responsabilidade da decisão (Pelaez $\left.{ }^{25}, 1988\right)$.

Além da manifestação do consentimento, o sujeito da pesquisa deverá assinar um formulário de consentimento. O consentimento do participante é de natureza ética, mas o formulário de consentimento é uma exigência legal (Hossne, Vieira ${ }^{17}$, 1995). O formulário de consentimento é um documento que deve ser redigido com linguagem acessivel e fazer parte do protocolo de pesquisa. Esse termo deve ter duas vias, ser assinado pelo sujeito da pesquisa e uma delas ser entregue ao participante.

\section{ANÁLISE DE RISCOS E BENEFíCIOS}

A análise crítica de riscos e benefícios é fundamental. Para realizar qualquer projeto de pesquisa que envolva ser humano, o pesquisador tem, obrigatoriamente, que refletir sobre os aspectos éticos da sua conduta. Ele tem a liberdade de propor um projeto de pesquisa para tentar responder a uma inquietação ou a uma demanda específica, mas também deve ter a preocupação sobre as conseqüências do que está propondo (Palácios et al. ${ }^{23}$, 2002).

Sempre que ocorre um avanço científico ou tecnológico, a humanidade vê-se diante da possibilidade de obter beneficios, mas também de ter que conviver com os riscos (Freire-Maia ${ }^{11}$, 1990). Em todas as modalidades de pesquisa envolvendo seres humanos, deve-se analisar criteriosamente os riscos e beneficios do experimento. O risco na pesquisa com seres humanos deve ser entendido como probabilidade de dano que, obrigatoriamente, estará associado ao experimento. Potencialmente, todo experimento pode provocar danos eventuais ou permanentes de natureza física, psicológica, social, moral, intelectual, cultural, espiritual e econômica. Até mesmo as intervenções terapêuticas de rotina, estão associadas a efeitos colaterais (Hossne, Vieira ${ }^{17}$, 1995).

Os riscos de um experimento podem ser avaliados através da análise de pesquisas realizadas anteriormente em laboratório, em animais e em outros grupos de humanos. Toda experimentação com seres humanos deveria ser, obrigatoriamente, precedida de testes em animais, quando seriam estimados seus riscos. Quando forem observadas reações adversas no experimento com animais, a pesquisa com humanos dever ser suspensa ou cercada de cuidados adicionais. Contudo, a ausência de efeitos danosos em animais não garante a segurança do tratamento para o homem (Hossne, Viei$\left.\mathrm{ra}^{17}, 1995\right)$.

No Brasil, a resolução CNS 196 (1996) estabelece que o pesquisador deverá suspender imediatamente o experimento quando perceber a possibilidade ou a ocorrência de um risco ou dano ao sujeito da pesquisa, não previsto no termo de consentimento. Bem assim, se outro método em estudo oferecer maior vantagem aos participantes, o experimento deverá ser suspenso e todos os sujeitos terão direito de acesso ao método melhor. Se, porventura, ocorrer algum dano conseqüente do experimento, previsto ou não no termo de consentimento, o sujeito da pesquisa terá direito à assistência integral e fará jus a indenização.

\section{BIOÉTICA E PESQUISA CIENTÍFICA}

A bioética como conhecemos hoje nasceu nos Estados Unidos entre o final dos anos 1960 e o começo dos anos 1970, quando uma série de fatores 
históricos culturais chamaram a atenção para a ética aplicada. O termo "bioética" é um neologismo inventado pelo oncologista van Rensselaer Potter em 1970 e difundido graças ao seu livro Bioethics: bridge to the future em 1971 (Mori $\left.{ }^{20}, 1994\right)$.

A visão original da bioética focalizava-a como uma questão ou um compromisso mais global frente ao equilíbrio e preservação da relação dos seres humanos com o ecossistema e a própria vida do planeta, diferente daquele que acabou difundindo-se e sedimentando-se nos meios científicos a partir da publicação do livro The Principles of Bioethics, escrito por Beachamp e Childress, em 1979 (Costa et al. ${ }^{10}, 1998$ ). A mudança de significado tem acontecido sobretudo porque, ainda em 1971, fundou-se o Kennedy Institute for Study of Human Reproduction and Bioethics, na Georgetown University de Washington (DC), e porque os cientistas do Kennedy Institute têm usado o termo num sentido completamente diferente daquele de Potter $\left(\right.$ Mori $\left.^{20}, 1994\right)$.

A obra de maior colaboração inter- e multidisciplinar produzida até o presente momento na área de Bioética, Encyclopedia of Bioethics, ao definir o que é bioética muda significativamente sua conceituação entre primeira (1978) e segunda edição (1995) (Pessini, Barchifontaine ${ }^{26}$, 1998). A bioética é definida como sendo "o estudo sistemático das dimensões morais - incluindo visão, decisão e normas morais - das ciências da vida e do cuidado da saúde, utilizando uma variedade de metodologias éticas num contexto multidisciplinar" (apud Pessini, Barchifontaine ${ }^{26}$, 1996).

Deram origem à reflexão bioética principialista: o Relatório Belmont, da Comissão Nacional Para a Proteção dos Seres Humanos da Pesquisa Biomédica e Comportamental (1978) e a obra clássica, Principles of Biomedical Ethics, de T. L. Beauchamp e J. F. Childress (Pessini, Barchifontaine ${ }^{26}$, 1996).

O Relatório Belmont foi oficialmente divulgado em 1978 e causou grande impacto. Tornou-se a declaração principialista clássica, não somente para ética ligada à pesquisa com seres humanos, já que acabou sendo também utilizada para reflexão bioética geral. Os três princípios identificados pelo Relatório Belmont foram o respeito pelas pessoas (autonomia), a beneficência e a justiça (Pessini, Barchifontaine ${ }^{26}$, 1996).

No Brasil, a resolução CNS 196 (1996), que trata de pesquisa com seres humanos, incorporou os princípios da Bioética em suas recomendações e os relaciona ao consentimento livre e esclarecido, à ponderação entre riscos e beneficios, à garantia de que os riscos previsíveis serão evitados e à relevância social da pesquisa.

O princípio da autonomia deve ser contemplado no desenvolvimento de experimentos com seres humanos através da obtenção do consentimento livre e esclarecido do sujeito, objeto da pesquisa. Ele representa um dos pilares éticos na execução dessa modalidade de pesquisa. O consentimento é o livre exercício da autonomia do voluntário.

O princípio da beneficência se vincula à análise criteriosa entre riscos e beneficios, sendo a maximização dos benefícios o caminho ideal para o desenvolvimento de pesquisa com seres humanos.

É possivel se prever os danos de um experimento através das pesquisas anteriormente realizadas: com animais, em laboratório, in vitro e, até mesmo através de simulações computadorizadas. Esse material pode ser obtido através de um levantamento bibliográfico criterioso. E, desse modo, há observância ao princípio da não maleficência, que está representado nas pesquisas com seres humanos pela garantia de que os danos previsíveis serão evitados.

A relevância social da pesquisa que envolve seres humanos e sua contribuição para voluntários e sociedade, simbolizam o princípio da justiça. O conceito de equidade, que pertence ao íntimo do principio da justiça, deve ser contemplado através da minimização do ônus para os sujeitos vulneráveis.

Os principios da Bioética devem ser considerados na execução de todas pesquisas que envolvem seres humanos. Esse é o caminho que garantirá à sociedade que esses experimentos tiveram a preocupação em preservar a dignidade dos seres humanos.

\section{CONSIDERAÇÕES FINAIS}

Embora as preocupações com a ética na pesquisa e, em especial, aquela que envolve seres humanos, sejam anteriores ao surgimento da Bioética, essa disciplina tem contribuído de maneira significativa na reflexão do tema que, indubitavelmente, é pertinente e atual.

A Bioética promove essa reflexão e suas discussões representam, agudamente, a vertente de pluralidade que cabe atribuir a nossas sociedades tecno-científicas, numa leitura que espelhe efetivamente quantos são os caminhos e quantas as trocas que temos que fazer no mundo atual. Hoje é 
praticamente impossivel seguirmos acreditando na vigência de um fundamento comum e hegemônico, capaz de manter sua primazia como modelo explicativo, sem nos submeter a coações adversas, resultantes do próprio conviver. O debate bioético, desse modo, desponta como uma forma de argumentação aberta, em movimento, cuja pretensão distancia-se muito do querer forçar o compartilha-

\section{REFERÊNCIAS}

1. Araújo LZ. Verificação da utilização de seres humanos e animais, em pesquisas científicas, frente aos fundamentos e preceitos da Bioética. 1999. (Dissertação de Mestrado). Universidade Federal Fluminense, Universidade Federal de Alagoas, Escola de Ciências Médicas de Alagoas.

2. Araújo LZ, Duarte ME. Verificação da utilização de seres humanos e animais, em pesquisas cientificas, frente aos fundamentos e preceitos da bioética. Odontologia e Sociedade 2000; 2(1/2):45-57.

3. Beaumont W. Experiments and observations on the gastric juice and the physiology of digestion. Plattsburg: FP Allen, 1883.

4. Beecher HK. Consent in clinical experimentation: mith and reality. Journal of American Medical Association - JAMA 1966; 195(1):34-35.

5. Beecher HK. Ethics and clinical research. N Eng J Med 1996; 274:1354-60.

6. Calvo JM. Hiroshima en el Oeste, Bogotá: Diario Ocho Columnas del 25 febrero 1971; 4.

7. Caplan AC. Twenty years after: the legacy of Tuskegee syphilis study. When evil intrudes. Hasting Center Reports. 1992; 22:6-15

8. Conselho Nacional de Saúde (Brasil). Resolução $n^{\circ} 1 / 88$. Bioética 1995, 3(2):137-54.

9. Conselho Nacional de Saúde (Brasil). Resolução $\mathrm{n}^{\circ}$ 196/96. Bioética 1996, 4(2),Supl:15-25.

10. Costa SI, Garrafa V, Oselka G. Apresentando a Bioética. In: Costa SI, Garrafa V, Oselka G (org.). Iniciação à Bioética. Brasilia: Conselho Federal de Medicina. 1998. p.13-18.

11. Freire-Maia A. Alguns aspectos da ética médica e científica. Ciência e Cultura 1990, 42(12):1144-1148.

12. Gafo J. La experimentación humana. In: Gafo J. Ética y legislación en enfermería. Madrid: Universita, 1994: 207-31.

13. Garrafa V. Bioética e Ciência - até onde avançar sem agredir. In: Costa SI, Garrafa V, Oselka G (org.). Iniciação à Bioética. Brasília, Conselho Federal de Medicina. 1998. p.99-110. mento das mesmas convicções a todos os membros da sociedade (Araújo, Duarte ${ }^{2}, 2000$ ).

Para concluir, no nosso entendimento as pesquisas científicas, principalmente aquelas que envolvem seres humanos, devem e podem ser executadas dentro de padrões éticos. Mas, a simples observância de normas, leis e recomendações éticas não garantirá a eticidade da pesquisa. A discussão sobre o tema deve ser incentivada e estar presente nos cursos de graduação e pós-graduação, bem como nos eventos e periódicos científicos.

14. Godin MA, Glantz LH. Children as research subjects, sciences, ethics \& law. New York: Oxford University, 1994; 23.

15. Gracia D. Investigação clínica. In: Profesión médica: investigación e justicia sanitaria. Santa Fé de Bogotá: Buho, $1998 ; 105$.

16. Hossne WS, Freitas CB. Relato do Trabalho. Bioética 1996; 4(2), Supl:15-25.

17. Hossne WS, Vieira S. Experimentação com seres humanos: aspectos éticos. In: Segre M, Cohen C (org.) Bioética. São Paulo, EDUSP. 1995. p.127-146.

18. Howard-Jones N. In: Council for International Organizations of Medical Sciences. Experimentation and medical ethics. Genebra, 1982; 453-95.

19. Kieffer GH. Experimentação humana. In: Kieffer, GH. Bioética, Madrid: Alhambra, 1983; 261-89.

20. Mori M. A Bioética: sua natureza e história. Humanidades 1994; 9(4):332-341.

21. Muñoz D, Fortes PA. O princípio da autonomia e o consentimento livre e esclarecido. In: Costa SI, Garrafa V, Oselka $\mathrm{G}$ (org.). Iniciação à Bioética. Brasília, Conselho Federal de Medicina. 1998. p.53-70.

22. Oliveira F. Bioética: uma face da cidadania. São Paulo: Moderna. 1997.

23. Palácios M, Rego S, Schramm FR. A regulamentação brasileira em ética em pesquisa envolvendo seres humanos. In: Machado RM, Carvalho DM, Block CK, Luiz RR, Werneck GL (org.) Epidemiologia. São Paulo, Atheneu. 2002. p.465-477.

24. Pappworth MH. Human Guinea pigs. Boston: Beacon, 1968.

25. Pelaez JH. Ética y experimentación médica. Acta Médica Colombiana 1988; 13(6):485-492.

26. Pessini L, Barchifontaine CP. Problemas atuais de Bioética. $3^{\mathrm{a}}$ ed. São Paulo: Edições Loyola. 1996. p.551.

27. Reich W. Research: history. In: Encyclopedia of Bioethics. New York: Wilkins, 1995, vol. 4.

28. Schramm FR, Kottow M. Nuevos desafios para los Comités de Bioética en investigación. Cuadernos Médico Sociales 2000; XLI (1-2). 